\title{
AN AUTOMATED REFERENCE POINT-LIKE APPROACH FOR MULTICRITERIA SHORTEST PATH PROBLEMS
}

\author{
João C. N. CLÍMACO ${ }^{1,2}$ José M. F. CRAVEIRINHA ${ }^{2,3}$ Marta M. B. PASCOAL PA $^{2,4}$ \\ ${ }^{I}$ Faculdade de Economia da Universidade de Coimbra, Avenida Dias da Silva, 165, 3004-512 Coimbra, Portugal \\ ${ }^{2}$ Instituto de Engenharia de Sistemas e Computadores - Coimbra, Rua Antero de Quental 199, \\ 3000-033 Coimbra, Portugal \\ jclimaco@inescc.pt \\ ${ }^{3}$ Departamento de Engenharia Electrotécnica e Computadores, Polo II da Universidade de Coimbra \\ Pinhal de Marrocos, 3030-290 Coimbra, Portugal \\ jcrav@deec.uc.pt
}

${ }^{4}$ Departamento de Matemática, Polo I da Universidade de Coimbra, Apartado 3008, 3001-454 Coimbra, Portugal marta@mat.uc.pt $(\bowtie)$

\begin{abstract}
In this paper we introduce a method of analysis for the automated ordering and selection of solutions of a multicriteria shortest path model. The method is based on a reference point approach, where the paths in a specific priority region are ranked by non-decreasing order of a Chebyshev metric. In order to list paths according with this objective function a labelling algorithm is proposed. The developed method is applied in a video-traffic routing context. Computational results are presented and analysed, for randomly generated networks of significant dimension.
\end{abstract}

Keywords: Routing, automated decision, multicriteria, reference point

\section{Introduction}

Nowadays the exponential and convergent development of informatics and telecommunications, including Internet, makes that, in many communication networks, important decisions of technical nature have to be made in short time periods or even in real-time. This is particularly relevant in the context of routing models involving the calculation and selection of routes (corresponding to loopless paths) for node to node traffic flows, which seek to optimize certain metric(s) while satisfying multiple constraints (usually designated as QoS - Quality of Service - requirements). The metrics to be optimised reflect the necessity of minimising the consumption of network resources (typically in terms of bandwidth and number of arcs used along a path) and of minimising the negative impact on all other traffic flows in the network, resulting from the use of a given path. The form of these objective functions and constraints 